(NASA-CR-194864) SYNTHESIS OF $N 94-23573$

PASSIVE MICROWAVE AND RADAR

ALTIMETER DATA FOR ESTIMATING

ACCUMULATION RATES DF POLAR SNOW

Unclas

(Kunsas Univ.) $6 \mathrm{p}$

$63 / 43 \quad 0202924$ 


\title{
SYNTHESIS OF PASSIVE MICROWAVE AND RADAR ALTIMETER DATA FOR ESTIMATING ACCUMULATION RATES OF POLAR SNOW

\begin{abstract}
Curt H. Davis
Radar Systems and Remote Sensing Laboratory, Electrical and Computer Engineering The University of Kansas, 2291 Irving Hill Road, Lawrence, Kansas 66045-2969, USA

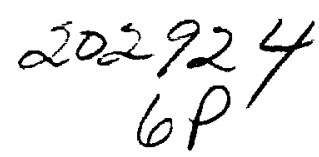$$
1 N-43-C 2
$$

In this paper, we compare dry-snow extinction coefficients derived from radar altimeter data with brightness temperature data from passive microwave measurements over a portion of the East Antarctic plateau. The comparison between the

extinction coefficients and the brightness temperatures shows a strong negative correlation, where the correlation coefficients ranged from -0.87 to -0.95 . The extinction coefficient of the dry polar snow decreases with increasing surface elevation, while the average brightness temperature increases with surface elevation. Our analysis shows that the observed trends are related to geographic variations in scattering coefficient of snow, which in tum are controlled by variations in surface temperature and snow accumulation rate. By combining information present in the extinction coefficient and brightness temperature datasets, we develop a model that can be used to obtain quantitative estimates of the accumulation rate of dry polar snow.

\section{INTRODUCTION}

The role of the ice sheets in global processes has become a major focus of research within the last two decades. Climatic warming caused by an increase in levels of carbon dioxide and other greenhouse gases has become a major political and environmental issue. Although the ice sheets play a critical role in global climatic processes, they remain one of the most poorly explored regions on the Earth. Satellite remote sensing systems provide the only proven means for observing the polar regions with the temporal resolution and spatial coverage required for meaningful ice-sheet studies [1]. Thus, it is important to compile new time series from existing satellite data and to continue the existing time series of data. This will provide a baseline set of geophysical measurements to improve our understanding of the role of polar processes in global climate. The baseline time series can then be analyzed to determine variations in geophysical parameters as evidence of climatic anomalies, trends, and even climatic change.

Passive microwave radiometers have been used to produce images of the polar regions since the early 1970s. Spatially varying patterns of microwave brightness temperature have resembled geographic variations in snow accumulation in some areas and physical temperature in others. For dry polar snow, the microwave emissivity depends strongly upon the snow grain size distribution with depth, which is determined primarily by accumulation rates and snow temperature. Using radiative transfer theory, Zwally [2] and Comiso et al. [3] correlated snow grain size with measured emissivity to calculate accumulation rates at a few selected sites in Antarctica. These investigations showed that emitted energy from depths up to 20 $m$ contribute to the observed radiometric brightness temperature.

Satellite radar altimeters have been used to measure surface elevations over the ice sheets. Recent work has shown that the shape of altimeter retum waveforms from the ice sheet is significantly affected by sub-surface volume scattering [4], [5]. By using a combined surface and volume-scattering model, Davis and Zwally [6] extracted dry-snow extinction coefficients from radar altimeter data. The extinction coefficient of snow characterizes the amount of signal penetration beneath the icesheet surface and is determined by its absorption and scattering properties. The smaller the extinction coefficient, the greater the amount of altimeter signal penetration.

\section{SATELLITE DATA COMPARISON}

In this section we compare active and passive microwave measurements over the Antarctic continent and show that geophysical properties of the ice sheet can be studied using these measurements. For this study, we selected a region from the East Antarctic ice sheet that covered a wide range of surface elevations. Datasets from the Geosat radar altimeter and the Scanning Multichannel Microwave Radiometer (SMMR) were obtained for the summer and winter months of 1986 and 1987 (Table I). The datasets are in a region bounded by the latitudes 71.5 to $72.1^{\circ} \mathrm{S}$ and the longitudes 80 to $100^{\circ} \mathrm{E}$. An elevation profile for the selected region is shown in Figure 1. The profile begins at an elevation of $2550 \mathrm{~m}$ at $80^{\circ} \mathrm{E}$, increases to an elevation of $3150 \mathrm{~m}$ at the ice divide $\left(94^{\circ} \mathrm{E}\right)$, and then decreases to an elevation of $3000 \mathrm{~m}$ at $100^{\circ} \mathrm{E}$.

Following the approach by Davis and Zwally [6], we fit a combined surface and volume-scattering model [5] to Geosat altimeter retum waveforms in $1^{\circ}$ subdivided regions for the two-month periods corresponding to the summer and winter seasons. After fitting the individual waveforms, we averaged the extinction coefficient $\left(k_{e}\right)$ values from the model fits together for each subdivided region. By fitting large numbers of individual waveforms, sufficient samples of the extinction coefficient are obtained to characterize seasonal and geographic differences in the surface properties of the ice sheet. For the SMMR satellite, we selected $10-\mathrm{GHz}$ data since they are closest to the $13.5 \mathrm{GHz}$ operating frequency of the Geosat altimeter. In this region the SMMR satellite made brightness temperature measurements every other day. Measurements at a selected longitude in each $1^{\circ}$ region were averaged together over twomonth periods to obtain the corresponding seasonal average.

A plot of the extinction coefficient vs. longitude for the summer and winter seasons of 1986 is shown in Figure 2. The data point at each longitude represents the sample mean for the region extending from the given longitude to a longitude one degree higher; i.e., the data point at $89^{\circ} \mathrm{E}$ corresponds to the region from $89-90^{\circ} \mathrm{E}$. The extinction coefficient decreases from a maximum value of $0.2 \mathrm{~m}^{-1}$ at $80^{\circ} \mathrm{E}$ to a minimum value of approximately $0.08 \mathrm{~m}^{-1}$ at $99^{\circ} \mathrm{E}$. This corresponds to penetration depths that range from 5.0 to $12.5 \mathrm{~m}$. The 1987 data show the same extinction coefficient variation with longitude. The 


\begin{tabular}{|c|c|c|c|c|}
\hline Area & Years & $\begin{array}{l}\text { Surmence } \\
\text { Mottdis }\end{array}$ & $\begin{array}{l}\text { Wintter } \\
\text { Monllis }\end{array}$ & Dota Region \\
\hline East Antarctica & 1986.1987 & $\mathrm{Jan}-\mathrm{rcb}$ & July-Aug & $71.5-72.1^{\circ} \mathrm{S} .80^{\circ} .100^{\circ} \mathrm{E}$ \\
\hline
\end{tabular}

- are-like region bounded in latitude

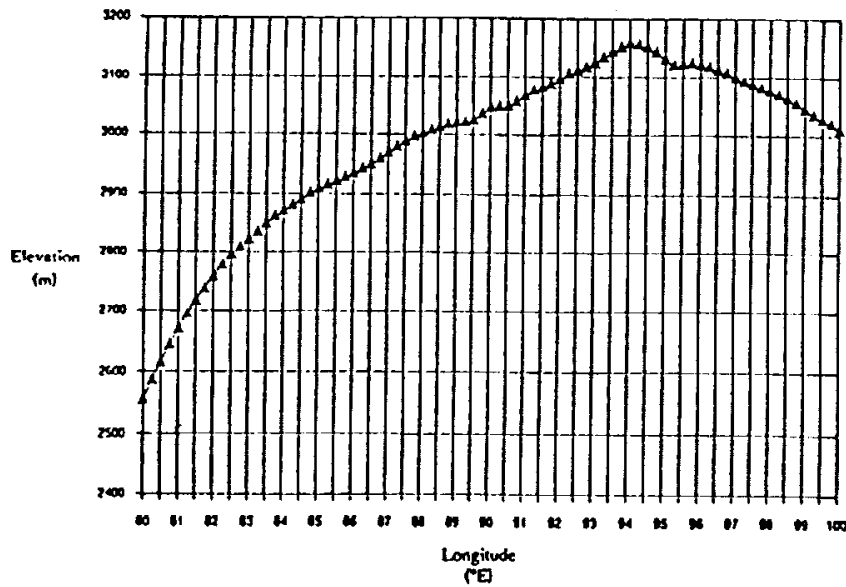

Figure 1. Elevation profile for the data region in East Antarctica from 80 to $100^{\circ} \mathrm{E}$ at a latitude of $72^{\circ} \mathrm{S}$.

decrease in $k_{e}$ from $80-93^{\circ} \mathrm{E}$ is strongly related to the increase in elevation from 2550-3125 $\mathrm{m}$ (Figure 1). Beyond the ice divide at $94^{\circ} \mathrm{E}$, the extinction coefficient experiences a shatp decrease even though the elevation drops slightly from 3150 $3000 \mathrm{~m}$. This decrease is probably related to a marked difference in the physical properties of the snow on either side of the ice divide.

The large-scale trend in the extinction coefficient is strongly related to surface elevation. Surface elevation can be used as a proxy for studying the effect of the mean annual surface temperature on the geophysical properties of the snow. As elevation increases, the mean annual surface temperature decreases. The growth rate of ice crystals in polar snow depends upon the mean annual surface temperature, where warmer temperatures produce higher growth rates. Larger growth rates increase the mean size of the snow grains, which increase the extinction coefficient. Thus, regions that have lower surface elevations generally have higher extinction coefficients.

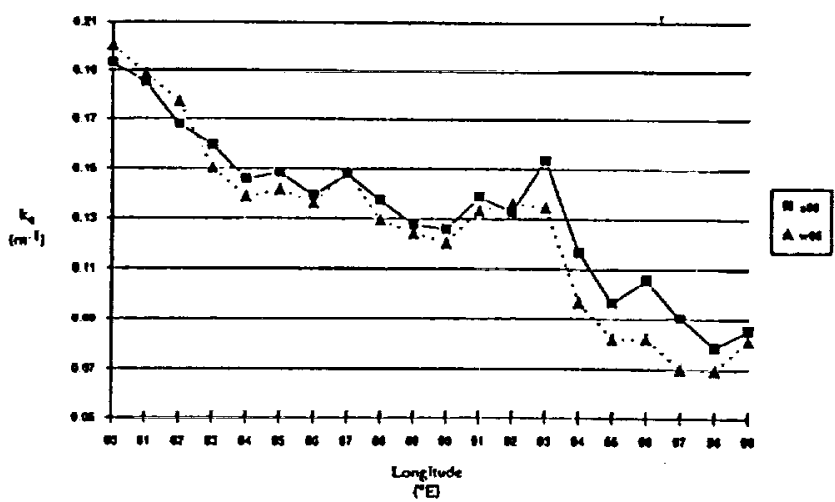

Figure 2. Extinction coefficient vs. longitude for the summer (boxes) and winter (triangles) seasons of 1986.

A plot of the 1986 mean brightness temperature vs. longitude is shown in Figure 3. For both seasons, the mean brightness temperature increases with longitude. The 1987 data showed the same increase with longitude. Theoretical modeling has shown that the microwave emissivity is controlled by variations in the density and grain size of polar firn as a function of depth [2], [3]. As the average grain size increases, the amount of emitted energy from greater snow depths is reduced because the upwelling radiation is attenuated due to an increase in the scattering loss. This causes the observed brightness temperature to decrease. Thus, the increasing brightness temperature with longitude suggests that the average grain size is decreasing.

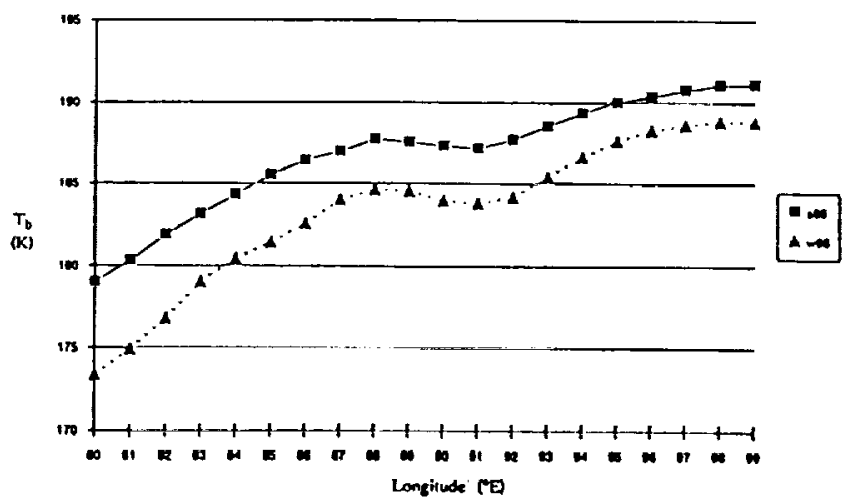

Figure 3. Mean brightness temperature vs. longitude for the summer (boxes) and winter (triangles) seasons of 1986.

Comparing the brightness temperature and extinction coefficient plots, we see that as the extinction coefficient decreases, the brightness temperature increases. Smaller average grain sizes decrease the extinction (primarily scattering) coefficient of snow. Thus, emitted energy from greater snow depths increases, thereby increasing the observed brightness temperatures. Linear correlation coefficients, $r$, were computed for the extinction coefficient and brightness temperature variations and these are summarized in Table II. The correlation coefficient varies from -0.87 to -0.95 , indicating a strong negative correlation. The negative correlation is due to the opposite effect that the snow grain size has on the observed brightness temperatures and extinction coefficients.

\begin{tabular}{lllll}
\hline \multicolumn{5}{c}{ Table II. $T_{b}-k_{e}$ Comelation Cocfficients } \\
\hline & Summer '86 & Winter 86 & Stummer '87 & Winter '87 \\
\hline Correlation Coefficient & -0.92 & -0.94 & -0.87 & -0.95 \\
\hline
\end{tabular}

While the large-scale trends in the extinction coefficient and brightness temperature datasets are clearly dominated by the snow grain-size dependence upon mean annual temperature, and hence elevation, there are some regional deviations from the overall trend. Note that in the region from $88-93^{\circ} \mathrm{E}$, both the extinction coefficient and mean brightness temperature are nearly constant as the elevation increases from 2950 to $3100 \mathrm{~m}$ for both the summer and winter seasons. Although the correlation coefficients computed for the extinction coefficient and brightness temperature variations with elevation are large, there are significantly smaller $(|r| \approx 0.76$ to 0.84$)$ than those in Table II. This suggests that the extinction coefficient and brightness temperature variations are influenced by another geophysical parameter.

\section{SYNTHESIS OF GEOSAT ALTIMETER AND SMMR DATA}

Work by Gow [7], [8] showed that the growth of snow grains in polar snow is not only dependent upon mean annual temperature, but also on the accumulation rate. For small accumulation rates, the snow grains are exposed to larger surface 
temperatures for a longer period of time. For high accumulation rates, the snow grains are buried at a greater rate and are insulated from the large temperature gradients at the surface. The net result is that the recrystallization rates of the snow grains increase as the accumulation rate decreases. Based upon this work, $Z$ wally [2] showed that the equation

$$
r(z)^{3}=r_{0}^{3}+k_{o} \frac{\rho z}{A} \exp \left[\frac{-E}{R T}\right]
$$

accurately fit crystal size data from pit studies, where $r(z)$ is the crystal radius at depth $z, r_{0}$ is the radius at the surface, $Q$ is the mean snow density, $A$ is the mean annual accumulation rate, $\mathrm{E}$ is the activation energy, $R$ is the gas constant, and $T$ is the mean annual surface temperature. Here we see that as $T$ increases, the growth rate increases, and conversely, as $\mathrm{A}$ increases, the growth rate decreases, just as described above. The extinction coefficient of snow is a linear combination of the absorption and scattering coefficients

$$
k_{e}=k_{a}+k_{s} \text {. }
$$

where the scattering coefficient, $k_{s}$, in tum depends upon the radius of the snow grain. A snow grain is usually comprised of one or two ice crystals and Gow [7] showed that the ratio is approximately 1.4:1. The absorption coefficient depends upon frequency, snow density, and the imaginary part of the dielectric constant of ice. Using dielectric properties reported by Matzler [9] and assuming a mean density of $0.45 \mathrm{~g} / \mathrm{cm}^{3}$, we calculated an absorption coefficient value of $k_{a}=0.04 \mathrm{~m}^{-1}$. The mean snow density over this region is nearly constant, and so the absorption coefficient is also assumed to be constant.

The brightness temperature measured at the surface of the ice sheet, $T_{b}$, is found by solving the radiative transfer equation and is given by

$$
\begin{aligned}
T_{b}= & (1-R) \sec \theta \int_{0}^{\infty}\left[T(z) k_{a}(z)+T_{s c}(z) k_{s}(z)\right] \\
& \exp \left\{\begin{array}{c}
-\sec \theta \int_{0}^{z}\left(k_{a}\left(z^{\prime}\right)+k_{s}\left(z^{\prime}\right)\right) d z^{\prime} \\
0
\end{array} d z\right.
\end{aligned}
$$

where $R$ is the power reflection coefficient, $\theta$ is the angle of transmission, $T(z)$ is the physical temperature at depth $z$, and $T_{s c}(z)$ is the scattering sounce term at depth $z$. This equation is extremely complicated to solve and requires detailed knowledge of the depth variations of temperature, the scattering source term, and the absomption and scattering coefficients. Previous investigations have used complicated numerical methods to solve this equation and relate the observed brightness temperatures at the ice-sheet surface to the underlying geophysical properties.

Here we propose a simple technique which can be used to relate $T_{b}$ to snow grain size without having to numerically solve (3). The technique is based upon the fact that the altimeter data provide an independent measurement of the extinction coefficient $k_{e}$. The depth of penetration, $d_{p}$, is inversely related to the extinction coefficient by

$$
\mathrm{d}_{\mathrm{p}}=\frac{1}{\mathrm{k}_{\mathrm{e}}} \text {. }
$$

This provides a reasonable estimate of the depth over which the various parameters in (3) contribute to the observed brightness temperature. We can solve (3) by assuming that all the terms inside the integral are constant with depth to obtain

$$
T_{b}=(1-R)\left[\frac{k_{a}}{k_{a}+k_{s}} T+\frac{k_{s}}{k_{a}+k_{s}} T_{s c}\right]
$$

Very little is known about the scattering source term, $T_{s c}$, but using the extinction coefficient data from the altimeter measurements we can approximate $\mathrm{T}_{\mathrm{sc}}$ using

$$
T_{S c}=T_{b}-\frac{k_{a}}{k_{e}}\left[T-T_{b}\right] \text {. }
$$

As $k_{e}$ approaches $k_{a}$ (no scattering), $T_{s c}$ becomes 0 , and as $k_{a}$ approaches $0, T_{b}$ approaches $T_{s c}$ as it should. In developing (5), it is assumed that the temperature is constant with depth, which is an approximation to the physical situation. Therefore, instead of using a surface temperature in (6), we calculate an effective mean snow temperature $\langle T\rangle$ by integrating a temperature profile model used by $Z$ wally [2] over the depth of penetration given in (4), i.e.

$$
\langle\mathrm{T}\rangle=\int_{0}^{\mathrm{d}_{\mathrm{p}}} \mathrm{T}(\mathrm{z}) \mathrm{dz} .
$$

This is then used along with the extinction coefficient data to estimate the scattering source tem in (6). Then, we can solve (5) for $k$, relating it to the brightness temperature, $T_{b}$. Using the same form as (7), (1) is integrated to obtain the effective mean grain size, $\langle r\rangle$, which is related to the mean surface temperature and accumulation rate. Assuming Rayleigh scattering and multiplying it by a dense medium coefficient $f_{d}$ $=0.3$ [3], we can solve the integrated form of (1) for the mean accumulation rate.

Figure 4 shows a plot of the mean accumulation rate vs. longitude. The accumulation rates vary from 4 to $18 \mathrm{~g} / \mathrm{cm}^{3}$ and agree with published maps of accumulation rates for the East Antarctic plateau. These maps are based upon sparse accumulation measurements from station data and show very little detail on a regional scale. The derived rates in Figure 4 show an excellent regional detail. From 80 to $93^{\circ} \mathrm{E}$, we see a steady decrease in accumulation rate from 9 to $4 \mathrm{~g} / \mathrm{cm}^{3}$. Also note that the minimum rate occurs at the ice divide (Figure 1). In this region, the opposing effects of mean annual temperature and accumulation rate compete for control of the mean grain size. The decrease in surface temperature with elevation causes the average grain size to initially decrease, which in tum causes the extinction coefficient to decrease and the brightness temperature to increase from 80 to $88^{\circ} \mathrm{E}$. However, the decreasing accumulation rate with increasing elevation in this region competes with the temperature effect, where the lower accumulations tend to produce a larger mean grain size. The accumulation effect on grain size balances out the temperature effect on grain size in the region from 88 to $93^{\circ} \mathrm{E}$, and we see a leveling off of the extinction coefficient and brightness temperature data. In the region east of the ice divide $\left(>93^{\circ} \mathrm{E}\right)$, we see a dramatic increase in the accumulation rate where the maximum value is four times the minimum value at the ice divide. In this region, the accumulation rate dominates the mean grain size. If temperature were the controlling factor, we 
would expect to see a increase in the extinction coefficient and a decrease in $T_{b}$ as the elevation decreases from 3150 to 3000 $m$. However, the exact opposite is true, indicating that the higher accumulation rates on the east side of the ice divide cause the mean grain size to continue to decrease, despite the decrease in elevation. This accounts for the further increase in brightness temperature and decrease in the extinction coefficient (Figures 2 and 3).

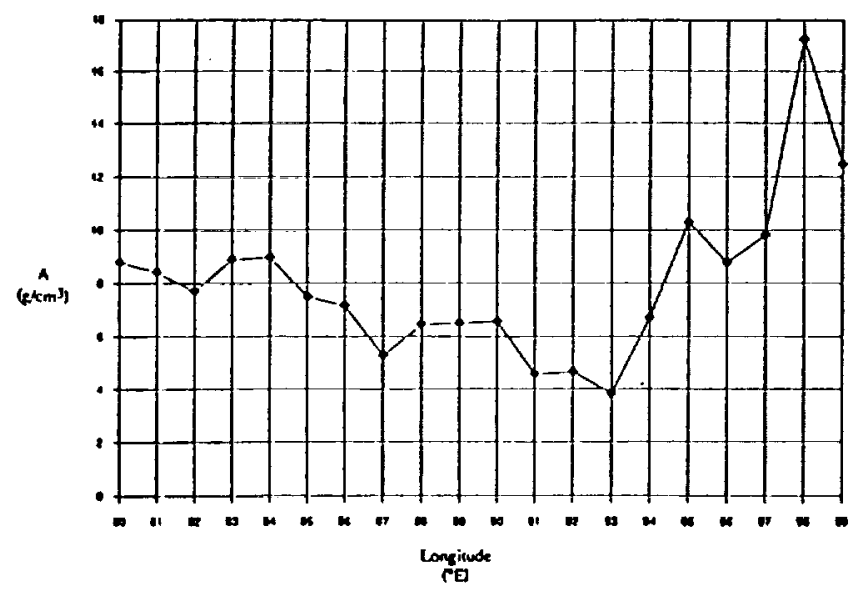

Figure 4. Accumulation rate vs. longitude derived from combining the extinction coefficient and brightness temperature data.

\section{CONCLUSION}

Clearly, for the region of East Antarctica studied here, the microwave brightness temperature is strongly related to the drysnow extinction coefficient. The synthesis of extinction coefficient and brightness temperatures data enabled reasonable estimates of the snow accumulation rate to be obtained. These estimates are the first to provide a detailed picture of small regional variations in the accumulation rate. The continuous time series of passive-microwave data (1978 to present) provides the opportunity to study long term variations in the geophysical properties of the continental ice sheets. Our ability to interpret these measurements can be significantly enhanced by including measurements from other satellite remote sensing systems. This type of data synthesis should be used to establish a baseline set of geophysical parameters estimates. This baseline set of measurements would be a valuable tool for studying long-term climatic variations of the ice sheets.

\section{REFERENCES}

[1] Thomas, R. H. et al. (1985), Satellite remote sensing for ice sheet research, NASA Tech. Memo. 86233.

[2] Zwally, H. J. (1977), Microwave emissivity and accumulation rate of polar fim, J. Glaciology, vol. 18, pp. 195215.

[3] Comiso, J. C., H. J. Zwally, and J. L. Saba (1982), Radiative transfer modeling of microwave emission and dependence on fim properties, Annals of Glaciology, vol. 3, pp. 54-58.

[4] Ridley, J. K. and K. C. Partington (1988), "A model of satellite radar altimeter retum from the ice sheets," Int. $J$. Rem. Sens., vol. 9, pp. 601-624.

[5] Davis, C. H. and R. K. Moore (1993), "A combined surface and volume scattering model for ice sheet radar altimetry," J. Glaciology, in press.

[6] Davis, C. H. and H. J. Zwally (1993), "Geographic and seasonal variations' in the surface properties of the ice sheets by satellite radar altimetry," $J$. Glaciology, in press.

[7] Gow, A. J. (1969), On the rates of growth of grains and crystals in south polar firn, J. Glaciology, vol. 8, pp. 241-252.

[8] Gow, A. J. (1971), Depth-time-temperature relationships of ice crystal growth in polar glaciers, CRREL Research Report no. 300.

[9] Matzler, C. and U. Wegmuller (1987), "Dielectric properties of fresh water ice at microwave frequencies," $J$. Phys. D: Appl.Phys., vol. 20, pp. 1623-1630. 


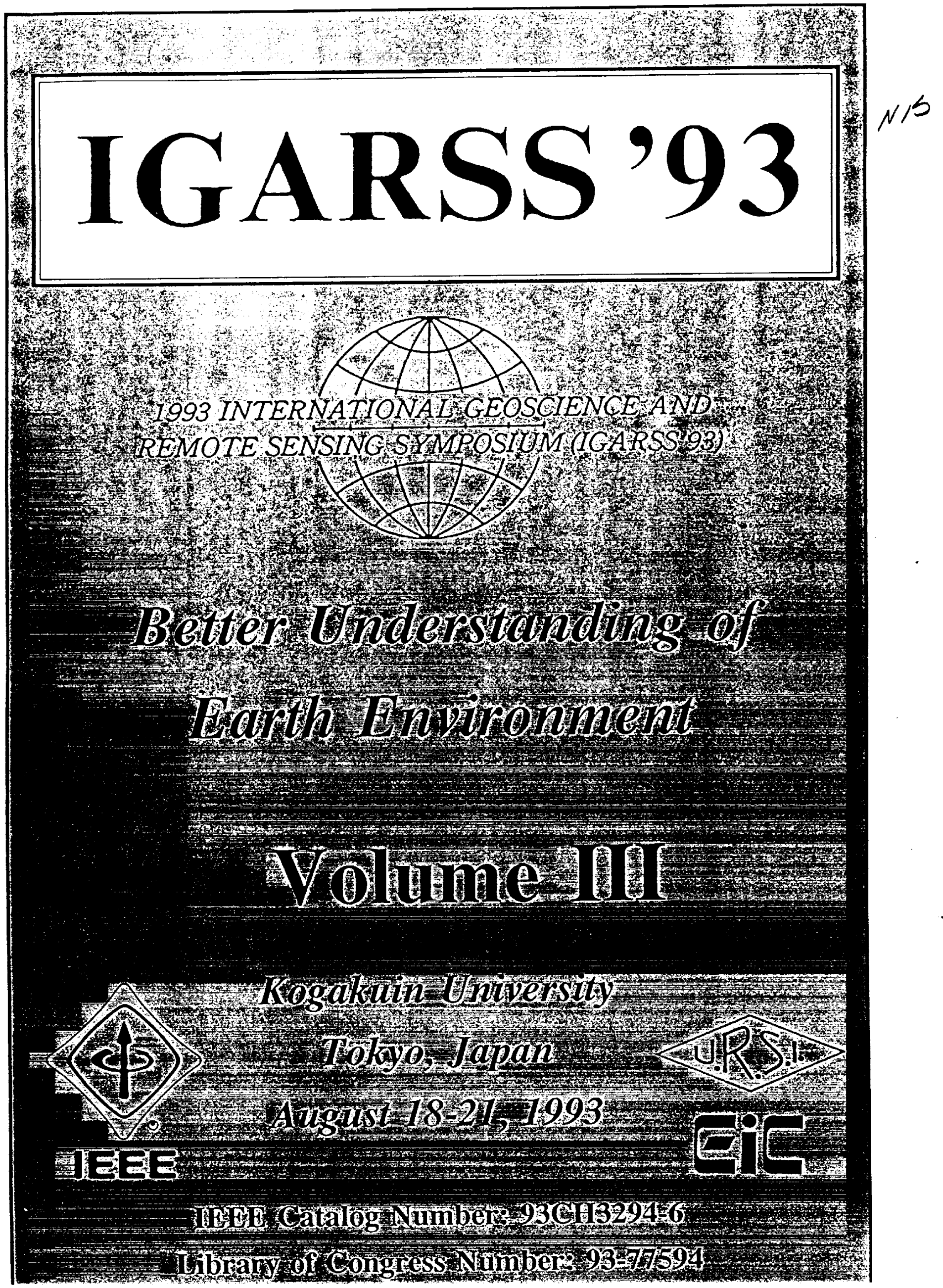


Fri-AM-I / Ann Arbor

Snow and Ice (4)

1. ANALYSIS OF BACKSCATTERING FROM SNOW COVERS ON ARCTIC AND 1035 ANTARCTIC SEA ICE

Tjuatja, S., A.K. Fung, J. Bredow, R. Hosseinmostafa, S. Gogineni and V. Lytle

2. DERIVING SNOW LIQUID WATER CONTENT USING C-BAND

POLARIMETRIC SAR

Shi, J., J. Dozier and H. Rott

3. MODELING AND OBSERVATION OF POLARIMETRIC SAR RESPONSE TO DRY SNOW

Shi, J., J. Dozier and H. Rott

4. EFFECT OF LAND-COVER TYPE AND SEASON IN MICROWAVE REMOTE SENSING OF SNOW

Jaaskelainen, V., L. Kurvonen and M. Hallikainen

5. DEPENDENCE OF RADAR BACKSCATTERING COEFFICIENT ON THE WATER EQUIVALENT AN OTHER SNOW CONDITIONS AT C-BAND OF ERS-1 SAR

Kondoh, A., N. Kamibayashi, T. Okada, S. Ishimori and S. Fujii

6. THE EFFECT OF SUB-SURFACE VOLUME SCATTERING ON THE ACCURACY OF ICE-SHEET ALTIMETER RETRACKING ALGORITHMS Davis, C.H.

Fri-AM-1/Edinburgh

Atmosphere (1) Constituents

1. SIMULTANEOUS MEASUREMENTS OF ATMOSPHERIC WATER VAPOR WITH MIR, RAMAN LIDAR AND RAWINSONDES

Wang, J.R., S.H. Melfi, P. Racette, D.N. Whitemen, R.K. Kakar, R.A. Ferrare, K.D. Evans and F.J. Schmidlin

2. LAS EXPERIMENT: EVIDENCE FOR DIRECT INJECTION OF WATER VAPOR INTO STRATOSPHERE AND STRATOSPHERIC OZONE DEPLETION BY HOX IN THE NORTHERN-HEMISPHERE LOW-LATITUDE REGION IN APRIL Matsuzaki, A.

3. POTENTIAL APPLICATION OF SOLAR OCCULTATION EXTINCTION MEASUREMENTS TO AEROSOL-CLOUD-INTERACTION STUDIES Wang, P., M.P. McCormick, L.R. Poole and G.S. Kent

4. REMOTE SENSING OF WEATHER FOR AVIATION MANAGEMENT Mahapatra, P.R. and D.S. Zmic

5. SEASONAL CHANGES IN THE TROPICS USING 5-DAY MEAN DATA Matsumoto, J. 